\title{
miR-122 promotes proliferation and invasion of clear cell renal cell carcinoma by suppressing Forkhead box $\mathrm{O3}$
}

\author{
WENYUAN NIE ${ }^{1 *}$, DONG NI $^{2 *}, \mathrm{XIN} \mathrm{MA}^{3}, \mathrm{YU} \mathrm{ZHANG}^{3}, \mathrm{YU} \mathrm{GAO}^{3}, \mathrm{CHENG} \mathrm{PENG}^{3}$ and XU ZHANG ${ }^{3}$ \\ ${ }^{1}$ Department of Urology, Chinese People's Liberation Army, 89th Hospital, Weifang, Shandong 261000; \\ ${ }^{2}$ Department of Urology, Union Hospital, Tongji Medical College, Huazhong University of Science and Technology, \\ Wuhan, Hubei 430022; ${ }^{3}$ Department of Urology, State Key Laboratory of Kidney Diseases, \\ Chinese People's Liberation Army General Hospital, PLA Medical School, Beijing 100853, P.R. China
}

Received February 13, 2018; Accepted October 5, 2018

DOI: 10.3892/ijo.2018.4636

\begin{abstract}
MicroRNAs (miRNAs) serve an important role in renal cancer, but renal cancer miRNA expression data remains inconsistent. Therefore, there is a requirement for integrated analysis of these data. An increasing number of studies demonstrate that miR-122 is dysregulated in numerous cancer types, including liver, lung and breast cancer, yet its role in clear cell renal cell carcinoma (ccRCC) remains unclear. In the present study, an integrated analysis of four ccRCC miRNAs expression datasets was performed and the expression of miR-122 in the present cohort was validated. The effects of cell proliferation, colony formation, migration and invasion of ccRCC cells in vitro were assayed following transfection with miR-122 mimics and inhibitor. The target gene of miR-122 was confirmed using a luciferase reporter assay, and a xenograft mouse model was used to determine the effect of miR-122 in ccRCC tumorigenicity in vivo. The present results demonstrated that patients with ccRCC with an increased miR-122 level in tumor tissues had a shortened metastasis-free survival time as indicated by The Cancer Genome Atlas-Kidney Renal Clear Cell Carcinoma dataset and the present ccRCC cohort. Overexpression of miR-122 in 786-O cells improved cell proliferation, colony formation, migration and invasion, while knockdown of miR-122 in SN12-PM6 cells inhibited cell growth, colony formation, migration and invasion.
\end{abstract}

Correspondence to: Dr Xu Zhang, Department of Urology, State Key Laboratory of Kidney Diseases, Chinese People's Liberation Army General Hospital, PLA Medical School, 28 Fuxing Road, Beijing 100853, P.R. China

E-mail: xzhang@foxmail.com

*Contributed equally

Abbreviations: ccRCC, clear cell renal cell carcinoma; GEO, Gene Expression Omnibus; EMT, epithelial-mesenchymal transition; miRNAs, microRNAs; NC, negative control; RT-PCR, reverse transcription-polymerase chain reaction

Key words: microRNA-122, Forkhead box O3, clear cell renal cell carcinoma, epithelial-mesenchymal transition, prognosis, biomarker
Western blot analysis and luciferase reporter assays were used to identify FOXO3 as a direct target of miR-122. The present results indicate that miR-122 serves a tumor-promoting role by direct targeting FOXO3 in ccRCC.

\section{Introduction}

Renal cell carcinoma is recognized as the third most common urologic malignancy, accounting for $\sim 3 \%$ of all malignant diseases in adults globally in 2017 (1). Worldwide, clear cell renal cell carcinoma (ccRCC) remain the most prevalent RCC subtype in 2017 (2). Although patients with localized ccRCC usually have a satisfactory prognosis, numerous patients are initially diagnosed at advanced stages, which are characterized by a high degree of malignancy, high rates of local invasion, and resistance to chemotherapy and radiotherapy $(3,4)$. Thus, an improved understanding of the mechanisms underlying ccRCC progression and metastasis is urgently required to identify novel biomarkers and develop more effective treatments for ccRCC.

MicroRNAs (miRNAs) are a class of small non-coding RNA molecules 22 nucleotides in length (5). A high level of a miRNAs in tissues can result in degradation of target mRNA or translation blockage $(6,7)$. With the growing number of miRNA chips in renal cancer, the miRNA expression data are frequently inconsistent (8). Therefore, comprehensive analysis of similar chips is of particular importance $(9,10)$. A number of studies used bioinformatics approaches to identify novel diagnostic and prognostic biomarkers; in particular, the analysis of miRNAs expression datasets is a beneficial tool $(11,12)$.

In the present study, four miRNA expression profiles of ccRCC from the Gene Expression Omnibus (GEO) datasets were analyzed, and then candidate miRNAs in The Cancer Genome Atlas (TCGA)-Kidney Renal Clear Cell Carcinoma (KIRC) dataset were validated, which revealed that miR-122 was highly expressed in ccRCC and is associated with poor survival time. miR-122 was one of the first examples of a tissue-specific miRNA of the liver that is involved in multiple metabolic processes, including fatty acid synthesis, cholesterol biosynthesis and $\beta$-oxidation (13-17). Numerous studies demonstrated that miR-122 is dysregulated in a number of cancer types, including liver, breast and renal cancer (16-18). In liver cancer, loss of miR-122 may result 
in the suppression of a hepatic phenotype and acquisition of invasive properties (19). In breast cancer, miR-122 has been determined to be rich in cancer exosomes that assist with distant metastasis by affecting their sugar metabolism (20). However, the current knowledge of miR-122 regulation in renal cancer at a molecular level remains limited.

Since predicted targets of miR-122 were enriched for the Forkhead box O (FOXO) family signaling pathway (21), it was hypothesized that miR-122 may function by targeting the FOXO3 mRNA FOXO3 belongs to the Forkhead gene family, encoding the transcription factor FOXO3, which exhibits consistent associations with longevity, apoptosis, proteostasis and autophagy (22-25). Notably, FOXO3 can suppress tumor growth (26). In leukemia and breast cancer cells, anticancer drugs upregulate $\mathrm{FOXO3}$ resulting in increased B-cell lymphoma-2 (Bcl-2) like 11 (Bim) expression and consequently inhibition of tumor growth (27-29). Additionally, FOXO3 downregulates $M y c$, a stimulator of tumor cell proliferation and survival $(30,31)$. The FOXO3 protein has been reported to be significantly downregulated in renal cancer, compared with adjacent tissues, but the FOXO3 mRNA level was not notably changed, indicating a post-transcriptional regulation may exist $(32,33)$.

In the present study, it was demonstrated that miR-122 is highly upregulated in ccRCC, and is associated with ccRCC metastasis. miR-122 promotes cell proliferation and invasion of ccRCC by targeting FOXO3 mRNA.

\section{Materials and methods}

Ethics approval and consent to participate. This study was approved by the Ethics Committee of Chinese People's Liberation Army (PLA) General Hospital (Beijing, China). Each enrolled patient signed written informed consent prior to sample collection. Animal experiments were approved by the Experimental Animal Ethical Committee of Chinese PLA General Hospital and were conducted in accordance with the Guide for the Care and Use of Laboratory Animals (34).

Patients and tissue samples. The inclusion criteria included: i) Clinical and imaging diagnosis of primary non-metastatic ccRCC; ii) aged 18-90 years old; and iii) underwent nephrectomy at Chinese PLA General Hospital. The exclusion criteria included: i) Missing imaging data; and ii) patients with severe liver and kidney disease, cardiovascular disease, blood disease or other malignant tumor types. A total of 46 ccRCC tissues, paired with adjacent non-tumor renal tissues, were recruited randomly from patients who were diagnosed with primary non-metastatic ccRCC and underwent nephrectomy at the Department of Urology, Department of People's Liberation Army (PLA) General Hospital (Beijing, China) between November 2013 and October 2015. The patient age range is 25-76 years, with a mean age of 54.2 years, and $50 \%$ were male and female. All specimens were pathologically confirmed to be ccRCC by senior pathologists of PLA General Hospital who were blind to the study. The patients were followed up for 15-48 months (median, 35 months). The nuclear grades and clinical stages were determined according to the 2009 Fuhrman nuclear grading system and Tumor-Node-Metastasis classification system, respectively, and 11 of them developed metastasis at the endpoint $(35,36)$.
Microarray data. The miRNA expression profiles were downloaded from the GEO database (http://www.ncbi.nlm.nih. gov/geo/; accession numbers, GSE24457, GSE23085, GSE71302 and GSE95385), which yielded 33 ccRCC tissue samples and 33 paired normal samples in total. The data was analyzed with the Morpheus Website (https://software.broadinstitute. org/morpheus/) using $\mathrm{P}<0.05$ and $[\log \mathrm{FC}]>1$ as cut-off criterion.

miRNA analysis of TCGA. OncoLnc online software (http://www.oncolnc.org) was used to validate the expression of miRNAs. The TCGA-KIRC datasets (https://portal.gdc. cancer.gov/projects/TCGA-KIRC) contains 506 ccRCC samples with clinical data.

miRNA target prediction and function analysis. A total of four different target prediction datasets were employed to identify the presumed targets of has-miR-122, including TargetScan v7.1 (http://www.targetscan.org/), miRDB (http://www.mirdb.org/), miR-TarBase v7.0 (http:// http://mirtarbase.mbc.nctu.edu. tw/php/index.php) and PicTar (http:// www.pictar.org/). Unique genes with target sites in 3'-untranslated region (UTR) were incorporated. Signaling pathway enrichment was performed using Kyoto Encyclopedia of Genes and Genomes (KEGG; http://www.genome.jp/) PATHWAY websites.

Cell culture. Human ccRCC cell lines 769-P, 786-O, Caki-1, A498, OS-RC-2 and SN12-PM6, the human renal proximal tubular epithelial cell line HKC and the 293T cell line were purchased from the Institute of Basic Medical Sciences Chinese Academy of Medical Sciences, China Infrastructure of Cell Line Resources (Beijing, China). 769-P, 786-O, Caki-1, A498, OS-RC-2 and SN12-PM6 cells were used for RT-qPCR. 786-O and SN12-PM6 cells were used for western blotting, immunofluorescence, MTS, colony formation, Transwell and wound-healing assay. The 293T cell line was used for Luciferase reporter assay. The cells were cultured in RPMI-1640 medium or Dulbecco's modified Eagle's medium (both from HyClone; GE Healthcare Life Sciences, Logan, UT, USA) with $10 \%$ fetal bovine serum (FBS; Gibco; Thermo Fisher Scientific, Inc., Waltham, MA, USA) and maintained in a humidified atmosphere containing $5 \% \mathrm{CO}_{2}$ at $37^{\circ} \mathrm{C}$.

Reverse transcription-quantitative polymerase chain reaction $(R T-q P C R)$. The total RNA was extracted from the cancer and adjacent normal tissues of the selected patients using TRIzol ${ }^{\circledR}$ reagent (Kang Wei Century Biological Technology Co., Ltd., Beijing, China). Reverse transcription of mRNA was performed using a One Step Realtime-PCR kit (Beijing Transgen Biotech Co., Ltd., Beijing, China) and miRNA cDNA synthesis was performed using a miRcute miRNA first-strand cDNA kit (Tiangen Biotech, Beijing, China), according to the manufacturer's protocols. The miR-122 expression level was detected by using a miRNA miRcute qPCR detection kit (Tiangen Biotech), according to the manufacturer's protocol, and miR-122 expression level was normalized to small nucleolar RNA U6 and calculated using the $2^{-\Delta \mathrm{Cq}}$ method, where $\Delta \mathrm{Cq}=\mathrm{Cq}$ miR-122 - Cq U6 (37). FOXO3 mRNA expression level was determined on the Applied Biosystems 7500 System using SYBR ${ }^{\circledR}$ Green (Tiangen Biotech Co., Ltd.). The thermal cycling conditions are $94^{\circ} \mathrm{C}$ for $30 \mathrm{sec}$, then 40 cycles for $94^{\circ} \mathrm{C}$ 
for $5 \mathrm{sec}$ and $64^{\circ} \mathrm{C}$ for $34 \mathrm{sec}$. Peptidylprolyl isomerase A was used to normalize the relative mRNA levels. The primers of FOXO3 are as follows: 5'-CAAAGCAGACCCTCAAAC-3' (sense) and 5'-CGGTATCACTGTCCACTT-3' (antisense). The primer sequences of peptidylprolyl isomerase $\mathrm{A}$ are as follows: 5'-ATGGTCAACCCCACCGTGT-3' (sense) and 5'-TCT GCTGTCTTTGGGACCTTGTC-3' (antisense).

RNAi treatment. Small interfering RNAs (siRNAs) against FOXO3 (siFOXO3), small interfering negative controls (siNC), mimics miR-122, mimics NC, inhibitor miR-122 and inhibitor NC were synthesized by Tiangen Biotech Co., Ltd.. siFOXO3 and siNC were being transfected into 786-O cells, and mimics miR-122 and inhibitor miR-122 and the corresponding NCs were transfected into 786-O and SN12-PM6 cells. Transfection was conducted using Lipofectamine ${ }^{\circledR} 2000$ (Invitrogen; Thermo Fisher Scientific, Inc.). Essential experiments were conducted $48 \mathrm{~h}$ after transfection. The sequences are as follows: siFOXO3 5'-CCAAUGUGUUUCAACUUUAAA-3' (sense), and 5'-UAAAGUUGAAACACAUUGGAG-3' (antisense); siNC 5'-UAGGAGUGGAGCAGAGUGAAG-3' (sense), and 5'-GCUAUGGGUGUCGAUAAUGAG-3' (antisense); miR-122 mimics 5'-UGGAGUGUGACAAUGGUGUUUG-3' (sense), and 5'-AACACCAUUGUCACACUCCAUU-3' (antisense); miR-122 NC 5'-UUCUCCGAACGUGUCACGUTT-3' (sense), and 5'-ACGUGACACGUUCGGAGAATT-3' (antisense); inhibitor miR-122 5'-CAAACACCAUUGUCACACUCCA-3' (sense), and 5'-GAGUGUGUGACAAUGGUGUUGC-3' (antisense); inhibitor NC 5'-CAGUACUUUUGUGUAGUACAA-3' (sense), and 5'-GUACUACACAAAAGUACGA-3' (antisense).

Western blotting. Total proteins of tissues or cells were extracted with radioimmunoprecipitation assay lysis buffer (Beijing Solarbio Science \& Technology Co., Ltd., Beijing, China) mixed with EDTA-free Protease Inhibitor (Roche Applied Science, Penzberg, Germany). Protein concentrations were detected using the bicinchoninic acid method. The proteins $(5 \mu \mathrm{g})$ were separated using $12 \%$ SDS-PAGE, and then transferred to polyvinylidene difluoride membranes (EMD Millipore, Billerica, MA, USA). The membranes were blocked with $5 \%$ bovine serum albumin (Beijing Solarbio Science \& Technology Co., Ltd.) for $1 \mathrm{~h}$ at $37^{\circ} \mathrm{C}$ and then incubated with primary antibodies against FOXO3 $(1: 1,000$; cat. no. 2497; Cell Signaling Technology, Inc., Danvers, MA, USA), E-cadherin (1:1,000; cat. no. 24E10; Cell Signaling Technology, Inc.), N-cadherin (1:1,000; cat. no. D4R1H; Cell Signaling Technology), $\alpha$-smooth muscle actin (SMA; 1:200; cat. no. ab7817; Abcam, Cambridge, UK) and $\beta$-actin $(1: 2,000$; cat. no. TA-08; OriGene Technologies, Inc., Rockville, MD, USA) overnight at $4^{\circ} \mathrm{C}$ followed by horseradish peroxidase-conjugated secondary goat anti-rabbit and anti-mouse $\operatorname{IgG}(\mathrm{H}+\mathrm{L})$ antibodies (1:2,000; cat. no. ab97051 and ab97023, respectively; Abcam) incubation for $1 \mathrm{~h}$ at $37^{\circ} \mathrm{C}$. Immunoreactive bands of the proteins were normalized to $\beta$-actin and visualized using enhanced chemiluminescence detection reagent (Thermo Fisher Scientific, Inc.).

Immunofluorescence. After 24-h transfection the treated cells were seeded on coverslips. Following fixation with $4 \%$ paraformaldehyde-PBS for $10 \mathrm{~min}$ at room temperature, cells were permeabilized with $0.5 \%$ Triton X-100 for 15 min and blocked with bovine serum albumin (3\%) for $30 \mathrm{~min}$ at room temperature. The cover slips were incubated with primary anti-FOXO3 antibody at 1:200 dilution for $1 \mathrm{~h}$ at $37^{\circ} \mathrm{C}$ and then incubated with fluorescein isothiocyanate-conjugated goat anti-rabbit secondary antibodies (cat. no. TA130015; OriGene Technologies, Inc.) at 1:100 dilution for $1 \mathrm{~h}$ at $37^{\circ} \mathrm{C}$. Nuclei staining was counterstained with $0.2 \mathrm{mg} / \mathrm{ml}$ DAPI for $15 \mathrm{~min}$ at $37^{\circ} \mathrm{C}$. Stained cells were visualized under an Olympus confocal microscope at x200 magnification (Olympus Corporation, Tokyo, Japan).

Construction of plasmids. During plasmid construction, the open reading frame of FOXO3 $(2.5 \mathrm{ng} ; 0.25 \mathrm{ng} / \mu \mathrm{l})$ was cloned into the PLV-EGFP(2A) lentiviral (25 ng; $2.5 \mathrm{ng} / \mu \mathrm{l}$ ) vector (InovoGen Tech. Co., Beijing, China) between the sites of $\mathrm{XbaI}$ and EcoRI to generate PLV-EGFPFOXO3. The miR-122 segment (2.5 ng; $0.25 \mathrm{ng} / \mu \mathrm{l}$; InovoGen Tech. Co) was inserted into pLVshRNA-EGFP(2A) lentiviral vector ( $2.5 \mathrm{ng} ; 0.25 \mathrm{ng} / \mu \mathrm{l}$; InovoGen Tech. Co.) to generate PLV-EGFPmiR-122. The sequence of miR-122 segment is 5'-CCTTAGCAGAGCT GTGGAGTGTGACAATGGTGTTTGTGTCTAAACTATCA AACGCCATTATCACACTAAATAGCTACTGCTAGGC-3'. PLV-EGFPFOXO3, PLV-EGFPmiR-122 and PLV-EGFP empty vector (EV) were transfected into cells using Lipofectamine 2000 to synthesize FOXO3 overexpressed, miR-122 overexpressed and control ccRCC cells according to the aforementioned protocol. The subsequent experimentations were conducted two weeks after the transfection.

Luciferase reporter assay. The wild-type or mutated 3'-UTR of FOXO3 containing the miR-122 binding site was cloned into a psiCHECK2 vector (Promega Corporation, Madison, WI, USA) provided by Genewiz, Inc. (Beijing, China). To test the function of miR-122 on luciferase activity, 293T cells were co-transfected with luciferase reporter of wild-type (WT) or mutated (MUT) 3'-UTR and miR-122 mimics or control using Lipofectamine 2000. Cells were assayed using Dual-Luciferase ${ }^{\circledR}$ Reporter Assay System (cat. no. E1910; Promega Corporation) $24 \mathrm{~h}$ after transfection. Luciferase assays were measured on the basis of ratio of Renilla/firefly luciferase activities in accordance with the Dual-Luciferase Assay Manual (38). The luciferase activity of each control vector was set to 1 .

MTS assay. The treated cells were seeded into a 96-well plate ( $1 \times 10^{3}$ cells/well). At 0, 24, 48, 72, 96 and $120 \mathrm{~h}$ after seeding in $10 \%$ FBS RPMI-1640 medium at $37^{\circ} \mathrm{C}, 20 \mu \mathrm{l}$ Celltiter $96^{\circledR}$ AQueous One Solution (Promega Corporation) was added to the cells and then co-incubated for $2 \mathrm{~h}$ at $37^{\circ} \mathrm{C}$ prior to absorbance measurement. The absorbance was recorded at $490 \mathrm{~nm}$ using an automatic enzyme-linked immunosorbent assay reader (BioTek Instruments, Inc., Winooski, VT, USA) with a 96-well plate reader.

Colony formation assay. The treated cells were seeded on a 6-well plate at a density of $1 \times 10^{3}$ cells/well. After culturing in $10 \%$ FBS RPMI-1640 medium at $37^{\circ} \mathrm{C}$ for 14 days, the treated cells were fixed with $100 \%$ methanol for $15 \mathrm{~min}$ at room temperature and stained with $1 \%$ crystal violet for $20 \mathrm{~min}$ at 
room temperature prior to the colony numbers being counted. Colonies consisting of $\geq 50$ cells were counted under a light microscope at x200 magnification.

Transwell migration and Matrigel invasion assays. Transwell assays were performed in Transwell chambers (Corning Incorporated, Corning, NY, USA) containing polycarbonate membrane filters with a pore size of $8 \mu \mathrm{m}$. The membranes were coated with Matrigel $(200 \mathrm{ng} / \mathrm{ml}$; BD Biosciences, Franklin Lakes, NJ, USA) for the invasion assay. A total of $1 \times 10^{4}$ cells in $200 \mu 1$ serum-free RPMI-1640 medium were seeded in the upper chamber, and $500 \mu 1$ 10\% FBS RPMI-1640 medium was added into the lower chamber. After culturing for 12 (migration) or 24 (invasion) h at $37^{\circ} \mathrm{C}$, the cells that adhered to the lower surface of the Transwell chambers were fixed with $100 \%$ methanol for $15 \mathrm{~min}$ at room temperature and stained with $1 \%$ crystal violet for $20 \mathrm{~min}$ at room temperature. The cells were counted in five random fields under a light microscope at x200 magnification (Olympus Corporation; x200), and the mean values were then calculated.

Wound-healing assay. A wound-healing assay was performed in 6-well plates. A total of $2 \times 10^{5}$ treated cells were seeded on 6-well plates. After culturing in RPMI- 1640 medium at $37^{\circ} \mathrm{C}$ overnight, the confluent monolayer of cells was serum-starved and scratched using a sterile $200 \mu \mathrm{l}$ pipette tip. Images of the same position were captured using a light microscope at $\mathrm{x} 20$ magnification at 0,6 and $12 \mathrm{~h}$ after the scratching. The coverage of the scratching area was measured at five random positions for each well.

In vivo growth assay of xenograft tumor. A total of $1 \times 10^{7}$ ccRCC cells stably expressing plv-miR-122 or EV were subcutaneously injected into the left armpit of male BALB/c nude mice (4 weeks old; weight, $14 \pm 1.2 \mathrm{~g} ; 10$ mice/group; 20 mice in total), which were supplied by Animal Experiment Center of PLA General Hospital and maintained at a specific pathogen free facility with a constant humidity and temperature at $26^{\circ} \mathrm{C}$, filtered air, and free access to food and water at 12/12-h light/dark cycle. Following tumor formation, the tumor volume was calculated weekly by using the following formula: $\mathrm{V}\left(\mathrm{mm}^{3}\right)=0.5 \mathrm{x}$ length $(\mathrm{mm}) \mathrm{x}$ width $^{2}\left(\mathrm{~mm}^{2}\right)$. All mice were sacrificed by cervical dislocation for weight measurement of xenograft tumors eight weeks after the injection.

Statistical analysis. SPSS 23.0 (SPSS, Inc., Chicago, IL, USA) and Prism 5.0 (GraphPad Software, Inc., La Jolla, CA, USA) software were used for all statistical analyses. Normally distributed variables were presented as means \pm standard deviation and compared using unpaired Student's t-test or one-way analysis of variance. Multiple comparisons between the groups were performed using Student's-Newman-Keuls method.. Disease-free survival time was used for prognostic evaluation of patients with ccRCC, which was defined as the time from the date the patient underwent radical or partial nephrectomy to the date of local recurrence, distant metastasis or mortality. Association analysis between two variables were analyzed by linear regression. Prognostic analysis was performed using the Kaplan-Meier method with log-rank test. Pearson $\chi^{2}$ test was used for Table I. $\mathrm{P}<0.05$ was considered to indicate a statistically significant difference.

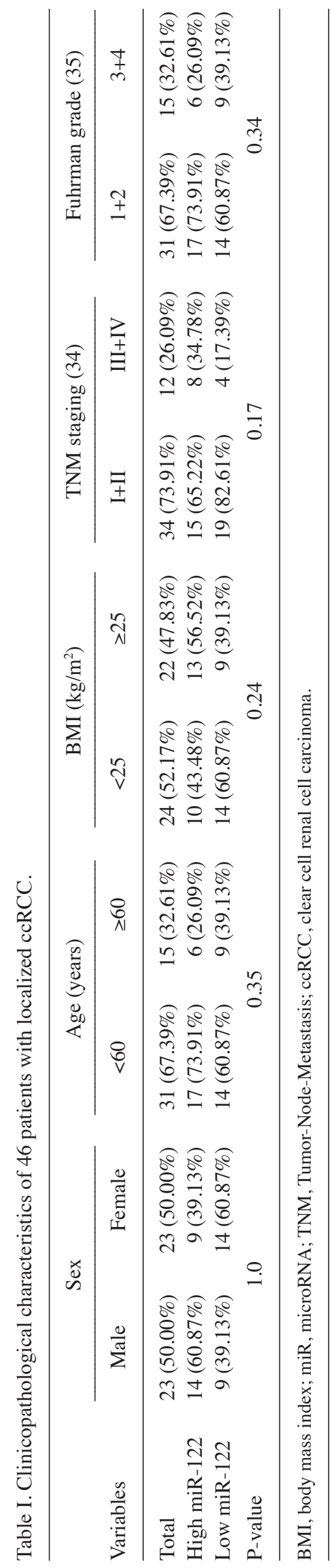


A

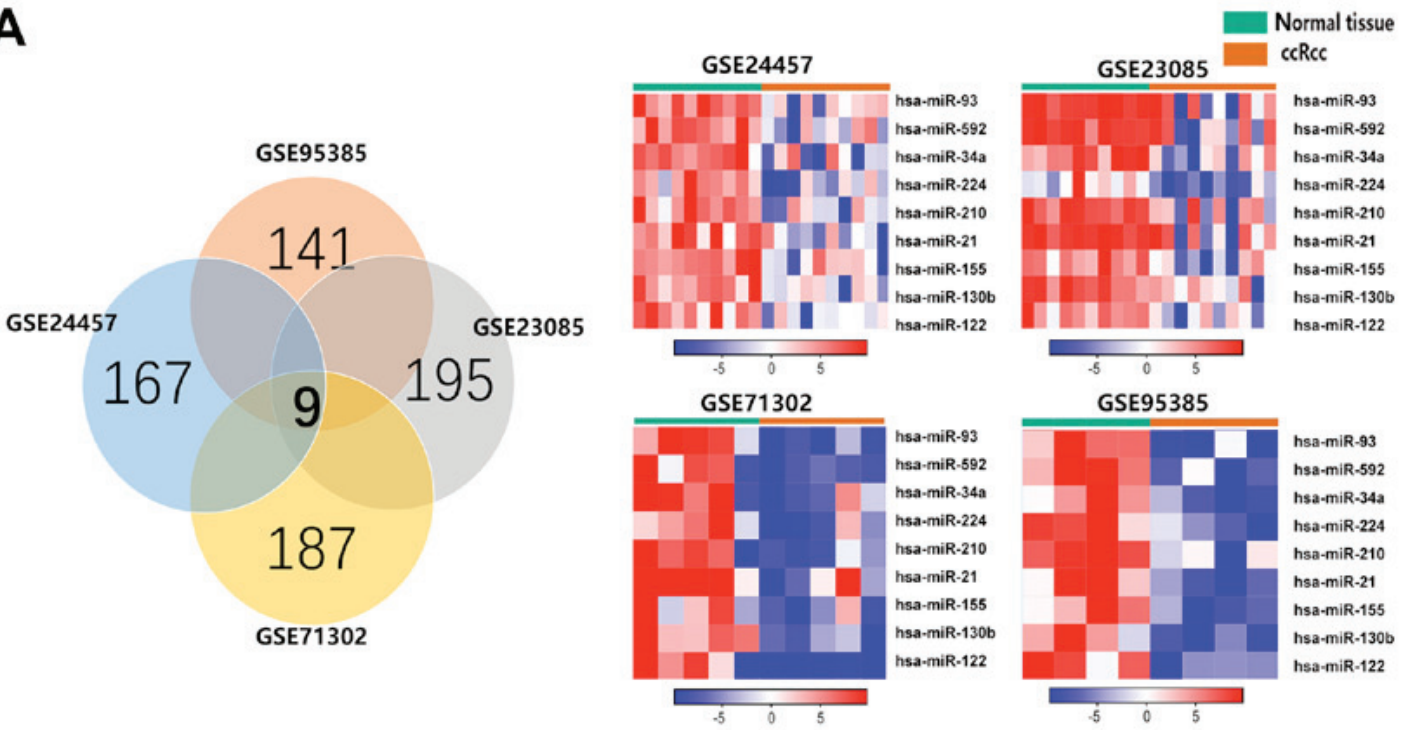

B
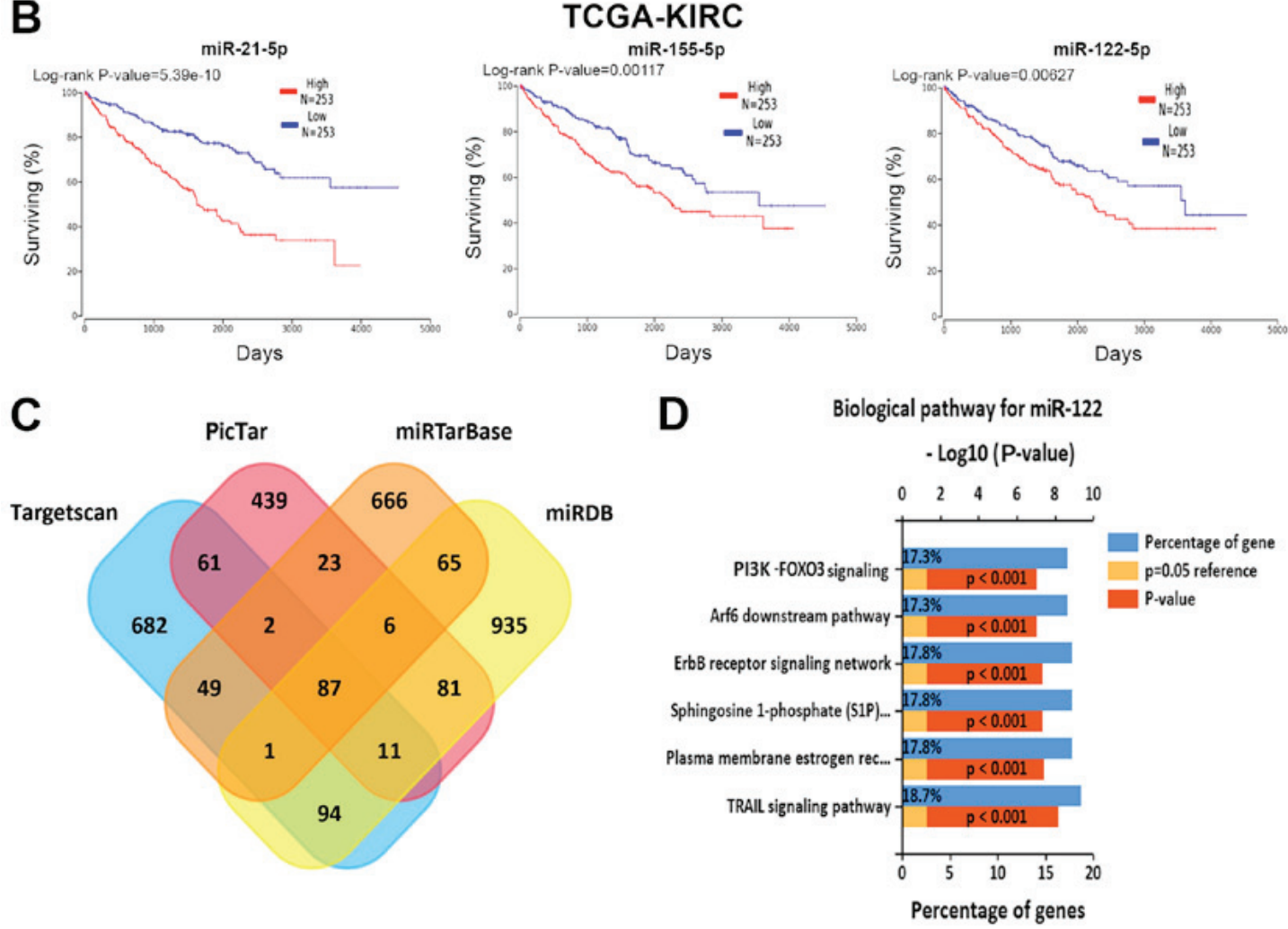

Figure 1. Integrated analysis identified significantly upregulated miRNAs in ccRCC. (A) Identification of nine upregulated miRNAs from the four cohort profile data sets (GSE24457, GSE23085, GSE71302 and GSE95385) using the Morpheus Website. Different color areas within the Venn diagram represent different datasets, the number of overlapping parts in the figure indicates the number of genes shared by the datasets, and the number of non-overlapping parts indicates the total number of genes in the dataset. (B) Kaplan-Meier analysis for overall survival time for different miRNA expression levels from TCGA-KIRC sequencing data. (C) Venn diagrams of putative miR-122 targets, which was predicted by TargetScan, PicTar, miR-TarBase and miRDB. The number of overlapping parts in the figure indicates the number of genes shared by the datasets, and the number of non-overlapping parts indicates the number of genes unique to the dataset. (D) The top six Kyoto Encyclopedia of Genes and Genomes pathways are cancer-specific pathways enriched for the miR-122 targets. miRNA, microRNA; ccRCC, clear cell renal cell carcinoma; FOXO3, Forkhead Box O3; PI3K, phosphoinositide 3-kinase; Arf6, ADP ribosylation factor 6; TRAIL, tumor necrosis factor-related apoptosis-inducing ligand; S1P, sphingosine 1-phosphate; TCGA-KIRC, The Cancer Genome Atlas-Kidney Renal Clear Cell Carcinoma.

\section{Results}

Integrated analysis identified significantly upregulated miRNAs in ccRCC. miRNA expression profiles GSE24457, GSE23085, GSE71302 and GSE95385 were downloaded from GEO. Upregulated miRNAs (167, 195, 187 and 141) were extracted from the GSE24457, GSE23085, GSE71302 and GSE95385 expression profile datasets, respectively. Following integrated bioinformatic analysis, nine consistently-upregulated miRNAs in ccRCC were identified from the four profile datasets (Fig. 1A). To further investigate whether the upregulated miRNAs associated with ccRCC survival time, OncoLnc software was employed and 

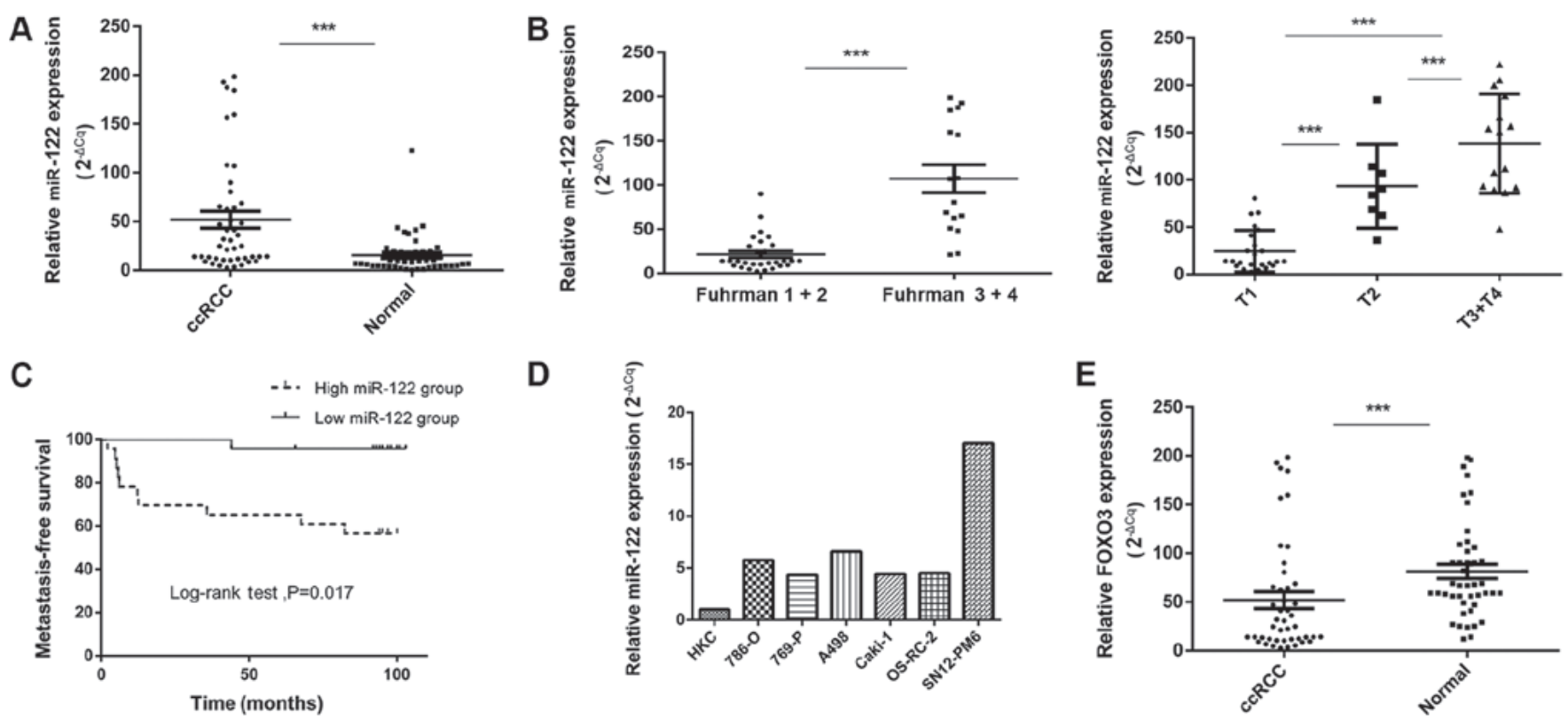

D
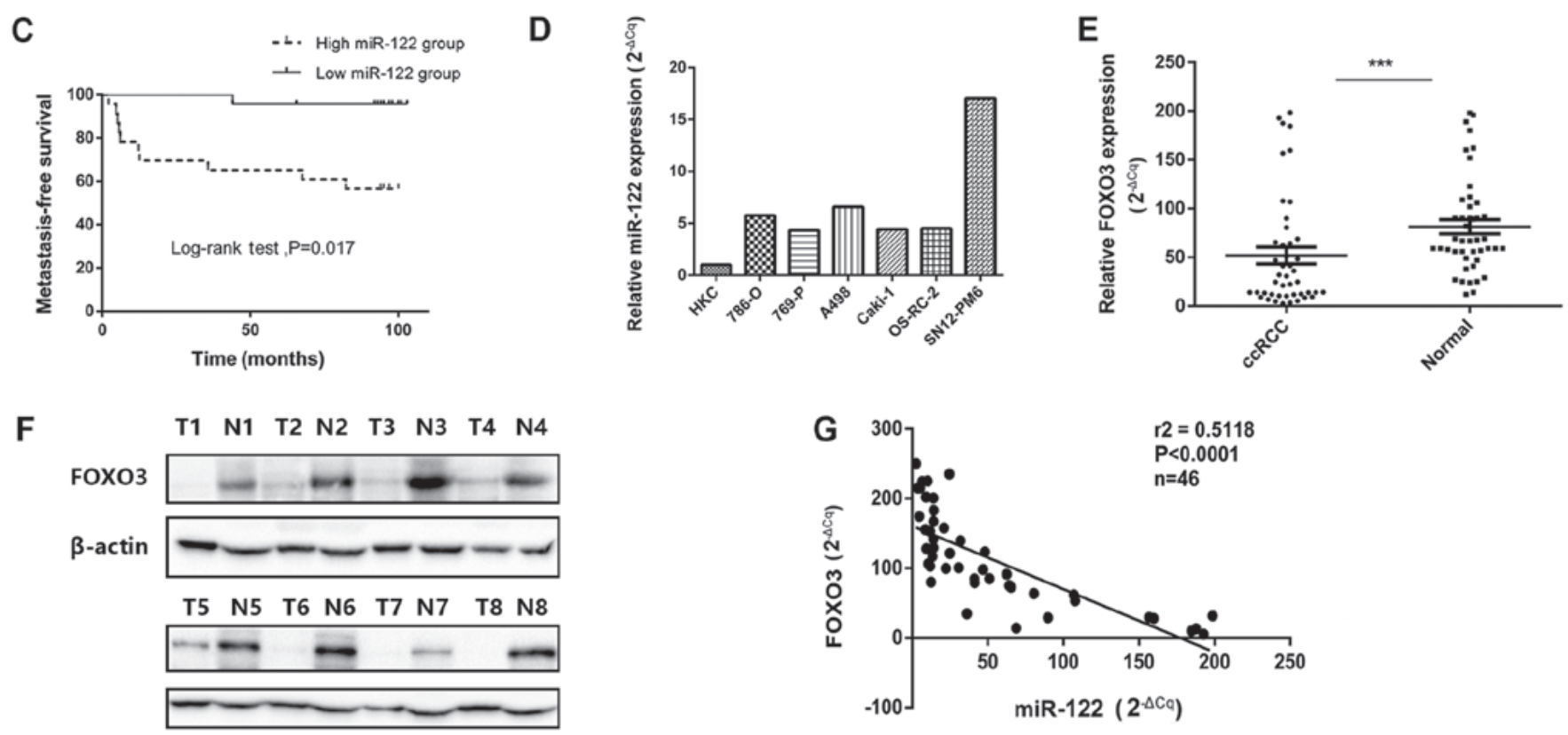

Figure 2. miR-122 expression levels in ccRCC tissues and cell lines as well as correlation with FOXO3 expression. (A) Increased miR-122 expression levels in ccRCC tissues, compared with adjacent normal tissues. (B) Association between miR-122 expression levels and Fuhrman grades and T stage of ccRCC. (C) Kaplan-Meier analysis of metastasis-free survival time in patients with ccRCC with high $(\mathrm{n}=23)$ and low $(\mathrm{n}=23)$ miR-122 levels at initial diagnosis ( $\mathrm{P}<0.01$; log-rank test). The median of the dataset served as the cutoff point. (D) miR-122 expression levels in various ccRCC cell lines, compared with HKC cells. (E) FOXO3 mRNA levels in ccRCC tissues, compared with normal adjacent tissues. (F) Protein levels of FOXO3 in clinical samples. (G) The negative correlation between FOXO3 mRNA levels and miR-122 levels $\left(\mathrm{n}=46, \mathrm{r}^{2}=0.5118, \mathrm{P}<0.0001\right)$. Data are presented as the mean \pm standard deviation $(* * * \mathrm{P}<0.001)$. miRNA, microRNA; ccRCC, clear cell renal cell carcinoma; FOXO3, Forkhead Box O3; T, tumor sample; N, normal sample.

analyzed (506 ccRCC samples) survival data were analyzed for the nine selected miRNAs. It was determined that high levels of miR-21, miR-155 and miR-122 were significantly associated with poor overall survival time (Fig. 1B). The other six miRNAs had no significant effect on ccRCC prognosis. Upregulation of miR-122 has been consistently observed in patients with ccRCC with poor overall survival time, but few articles have reported the functional importance of miR-122 in ccRCC pathogenesis $(39,40)$. The present study predicted the target gene of miR-122 using TargetScan v7.1, miRDB, miR-TarBase v7.0, and PicTar, and identified 87 consensus genes (Fig. 1C). Subsequently, KEGG pathway analysis of the 87 consensus genes was performed to clarify the potential biological functions of miR-122. Fig. 1D depicts the top six KEGG pathways enriched of the miR-122 targets, which are: PI3K-FOXO3 pathway, tumor necrosis factor-related apoptosis-inducing ligand signaling pathway, ErbB receptor signaling network, sphingosine 1-phosphate pathway, plasma membrane estrogen receptor signaling and the ADP ribosylation factor 6 downstream pathway. Following screening, it was determined that downregulation was only demonstrated for $\mathrm{FOXO} 3$ in ccRCC, so it was hypothesized that FOXO3 may be the direct target of miR-122.
Upregulation of miR-122 is associated with downregulation of FOXO3. To investigate the role of miR-122 in ccRCC, miR-122 expression was examined in a number of ccRCC lines and 46 pairs of ccRCC tissue samples (non-metastatic tumors and their adjacent normal tissue specimens) (Table I). Fig. 2A demonstrates that miR-122 was significantly upregulated in ccRCC tissues, compared with adjacent normal kidney tissues $(\mathrm{P}<0.001)$. Subsequently, miR-122 expression level in different Fuhrman stages and T stages of ccRCC tissues was analyzed. Compared with lower-Fuhrman-grade group (Fuhrman I+II) and T1-stage group, significantly increased levels of miR-122 expression were determined in the higher-Fuhrman-grade group (Fuhrman III+IV) and later T-stage groups (T2 and T3+T4) (Fig. 2B; P<0.05).

To investigate whether miR-122 expression is associated with the prognosis of renal cancer, 46 selected patients with primary non-metastatic ccRCC were followed up for 15-48 months (median, 35 months) post-operatively. Subsequently, the ccRCC dataset was ranked based on the miR-122 expression levels and the median of the dataset was selected as the threshold between the high miR-122 group and the low miR-122 group (n=23/group). Kaplan-Meier analysis 
demonstrated that patients in the high miR-122 group had a reduced metastasis-free survival time, compared with those in the low miR-122 group $(\mathrm{P}<0.01$; Fig. 2C). Furthermore, the expression of miR-122 was measured in a number of renal cancer cell lines. Compared with the HKC cell line, miR-122 expression was notably increased in the SN12-PM6 and A498 cell lines and had increased expression in 786-O, 769-P, Caki-1 and OS-RC-2 cell lines (Fig. 2D). These results were consistent with the miR-122 expression levels detected in the ccRCC tissues. Additionally, the FOXO3 expression in these specimens was examined, and $\mathrm{FOXO} 3$ expression in ccRCC cancer tissues was significantly reduced, compared with normal tissues $(\mathrm{P}<0.001$; Fig. $2 \mathrm{E})$. Western blot analysis also demonstrated reduced protein levels of FOXO3 in ccRCC cancer tissues, compared with adjacent normal tissues (Fig. 2F). Finally, miR-122 expression demonstrated a significant inverse association with $\mathrm{FOXO3}$ at mRNA levels $\left(r^{2}=0.5118, P<0.001\right.$; Fig. $\left.2 \mathrm{G}\right)$.

miR-122 promotes the proliferation and migration of ccRCC cells in vitro. To investigate the biological roles of miR-122 in ccRCC, miR-122 mimics were used to increase miR-122 expression and a miR-122 inhibitor was used to decrease miR-122 expression. 786-O cells, which have a low level of miR-122 expression (Fig. 2D), were transfected with miR-122 mimics to achieve significant miR-122 overexpression, compared with mimics NC $(\mathrm{P}<0.001$; Fig. 3A). Additionally, SN12-PM6 cells, which have a high level of miR-122 expression, were transfected with a miR-122 inhibitor to achieve a relatively low miR-122 expression, compared with inhibitor NC (Fig. 3B).

Subsequently, the two cell lines were then analyzed using an MTS assay. As depicted in Fig. 3C, overexpressing miR-122 in 786-O cells significantly enhanced growth, compared with those transfected with mimics $\mathrm{NC}(\mathrm{P}<0.05)$. Additionally, miR-122 expression was inhibited in SN12-PM6 cells significantly attenuated cell growth, compared with those transfected with inhibitor $\mathrm{NC}(\mathrm{P}<0.05)$. In the colony formation assay, the colony-formation ability was significantly increased in 786-O cells following transfection with the miR-122 mimics and significantly decreased in SN12-PM6 cells transfected with the miR-122 inhibitor, compared with NC $(\mathrm{P}<0.001$; Fig. 3D).

The effect of miR-122 on invasion and migration were examined by Transwell, Matrigel and wound healing assays. Fig. 3E depicts that the invasive and migratory abilities of 786-O cells were significantly enhanced following treatment with miR-122 mimics, compared with cells treated with miR-122 mimics NC $(\mathrm{P}<0.001)$, and the migration and invasion of SN12-PM6 cells were significantly attenuated following treatment with the miR-122 inhibitor, compared with inhibitor $\mathrm{NC}(\mathrm{P}<0.001)$. Wound healing assays demonstrated that miR-122 promoted 786-O cell migration following transfection with miR-122 mimics, and SN12-PM6 cells displayed decreased migratory capacity following treatment with the miR-122 inhibitor (Fig. 3F).

Additionally, two epithelial-mesenchymal transition (EMT)-associated genes ( $N$-cadherin and $E$-cadherin) were examined. The present results collectively indicated that mimics miR-122 significantly promotes the proliferation and migration of ccRCC cells, compared with mimics $\mathrm{NC}(\mathrm{P}<0.05$; Fig. 3G).

FOXO3 is a direct target of miR-122. As FOXO3 was predicted to be the target of miR-122 and has been demonstrated to be downregulated in ccRCC. It was hypothesized that upregulation of miR-122 may induce ccRCC malignancy by attenuating $\mathrm{FOXO} 3$ expression. Fig. 4A depicts the putative miR-122 targeting sites in FOXO3 3'-UTR. As depicted by Fig. 4B and $\mathrm{C}, \mathrm{FOXO} 3 \mathrm{mRNA}$ and protein expression are significantly decreased in 786-O cells following transfection with miR-122 mimics, compared with mimics $\mathrm{NC}(\mathrm{P}<0.001)$; however, FOXO3 expression is significantly increased in SN12-PM6 cells following transfection with miR-122 inhibitor, compared with inhibitor NC $(\mathrm{P}<0.001)$. Immunofluorescence assays demonstrated that $\mathrm{FOXO} 3$ protein levels were decreased in 786-O cells treated by miR-122 mimics, compared with cells transfected with miR-122 mimics NC, and FOXO3 protein levels were increased in SN12-PM6 cells following transfection with the miR-122 inhibitor, compared with NC (Fig. 4D). These data reveal that FOXO3 protein expression is negatively regulated by miR-122. Bioinformatic predictions validated one conserved miR-122 binding site on the 3'-UTR of FOXO3 mRNA. Subsequently, a 456-bp fragment was cloned from the FOXO3 3'-UTR containing the miR-122 bonding site into a luciferase reporter plasmid. The WT luciferase reporter plasmid or mutant MUT reporter plasmid was separately co-transfected with miR-122 mimics or mimics NC. The results revealed that miR-122 significantly repressed luciferase activity of WT reporter, compared with MUT reporter $(\mathrm{P}<0.01$; Fig. $4 \mathrm{E})$, indicating that miR-122 directly binds to the predicted site in the FOXO3 3'-UTR and negatively regulates $\mathrm{FOXO} 3$ expression.

miR-122 promotes cell proliferation and invasion by downregulating FOXO3. The present study examined whether FOXO3 reversed the oncogenic effects of miR-122 in ccRCC cells. Firstly, lentiviral FOXO3 particles (empty vector) were co-transfected with miR-122 mimics (mimics NC) in 786-O cells. RT-qPCR analysis confirmed that miR-122 mimics reduced $\mathrm{FOXO} 3$ expression, compared with mimics $\mathrm{NC}$ groups ( $\mathrm{P}<0.001$; Fig. 5A). Additionally, transfecting miR-122 inhibitor caused significant downregulation of miR-122 and significantly upregulation of FOXO3, compared with inhibitor NC groups $(\mathrm{P}<0.001$; Fig. 5B). In FOXO3 groups, the FOXO3 plasmid significantly attenuated the proliferative and invasive abilities of 786-O cells transfected with miR-122 mimics, compared with EV groups ( $\mathrm{P}<0.05$; Fig. $5 \mathrm{C}$ and $\mathrm{D})$. Subsequently, a rescue experiment was performed by co-transfecting FOXO3 siRNA or the siNC and the miR-122 inhibitor or inhibitor $\mathrm{NC}$ into SN12-PM6 cells. In siFOXO3 groups, FOXO3 downregulation effectively reversed the attenuation of SN12-PM6 cell invasion and proliferation induced by the miR-122 inhibitor, compared with siNC groups $(\mathrm{P}<0.05$; Fig. $5 \mathrm{E}$ and $\mathrm{F})$. These data reveal that miR-122 promotes proliferation and invasion of ccRCC by downregulating FOXO3.

miR-122 promotes tumor growth and cell invasion in vivo. A BALB/c nude mouse xenograft model and 786-O cells were employed to verify the function of miR-122 in ccRCC. 
A

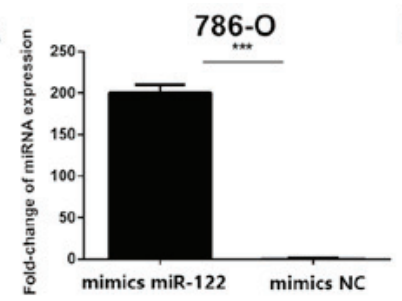

B 亳

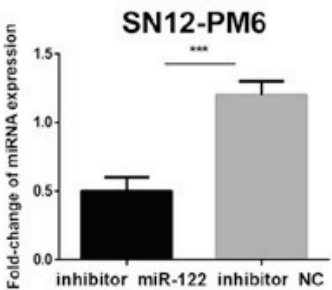

D

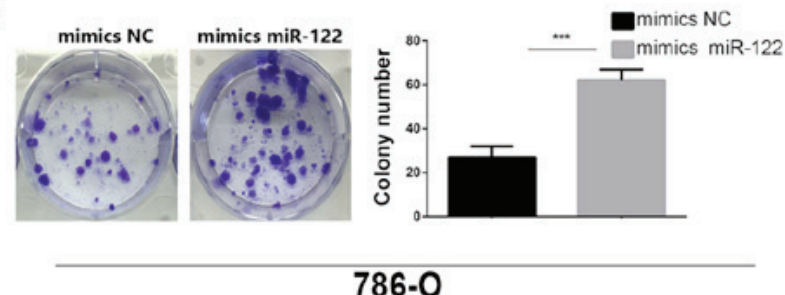

E
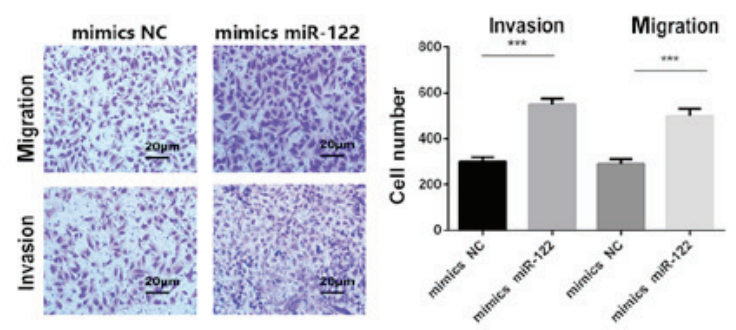

$786-0$

$\mathbf{F}$

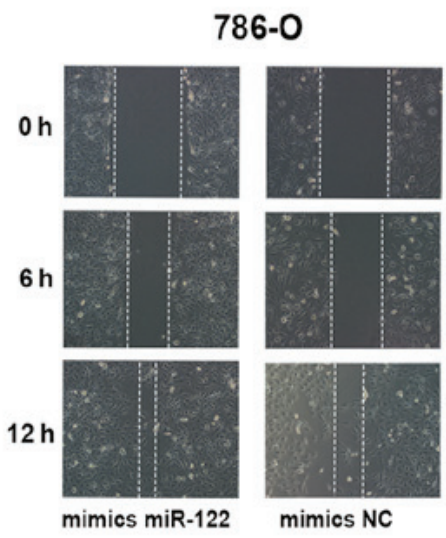

$6 \mathrm{~h}$

$12 \mathrm{~h}$
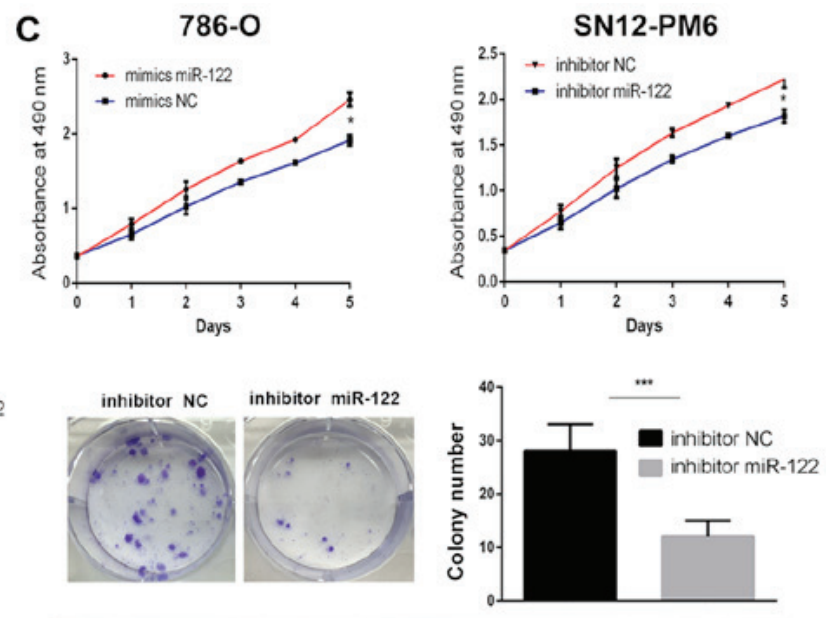

SN12-PM6
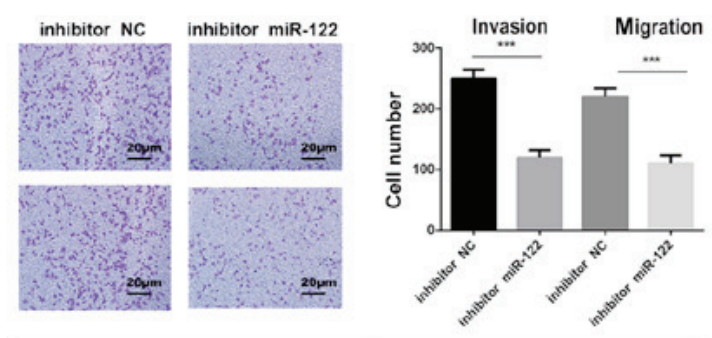

SN12-PM6
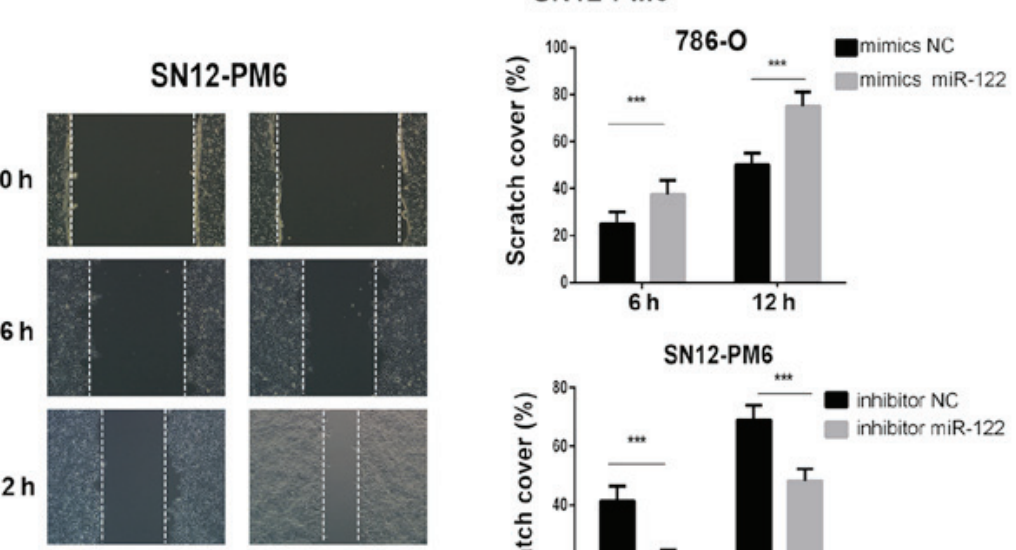

inhibitor miR-122 inhibitor NC

G
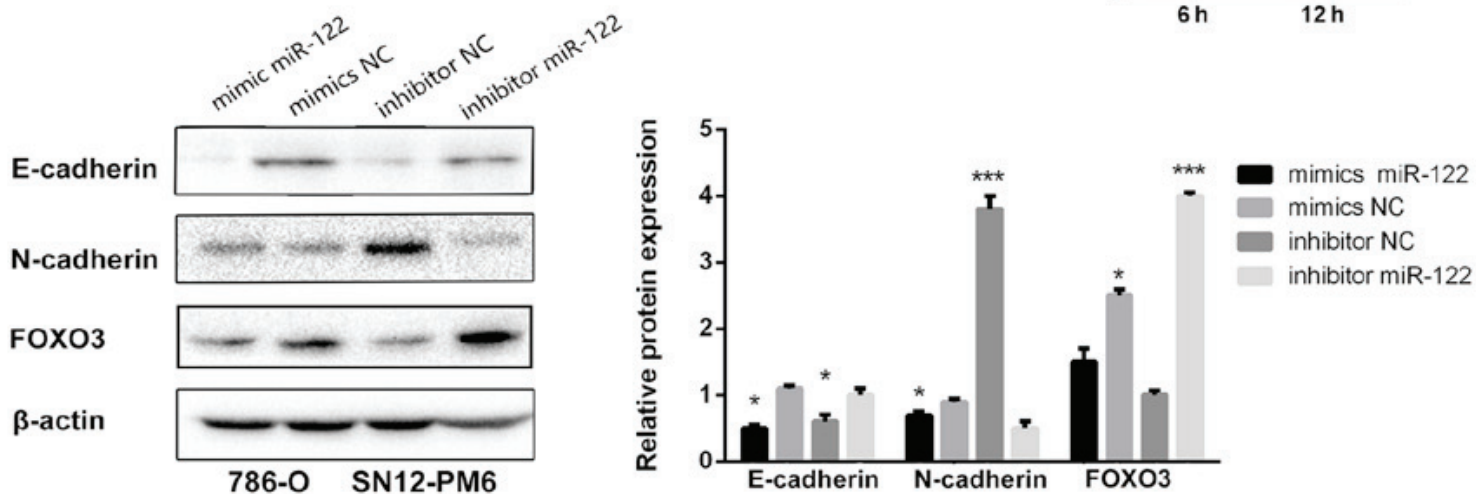

Figure 3. miR-122 promotes the proliferation and migration of ccRCC cells in vitro. Alteration of miR-122 expression levels in (A) 786-O or (B) SN12-PM6 cells following overexpression or suppression of miR-122, respectively. (C) MTS assay demonstrated that transfection of the miR-122 mimics promotes the proliferation of 786-O cells, while the miR-122 inhibitor reduces proliferation of SN12-PM6 cells. (D) The colony formation assay demonstrated the effect of miR-122 overexpression and suppression on 786-O and SN12-PM6 cells, respectively. (E) Representative images and cell quantifications of Transwell and Matrigel assays of 786-O and SN12-PM6 cells transfected with miR-122 mimics or NC or miR-122 inhibitor or NC. (F) The wound-healing assay indicated that the miR-122 mimics enhanced cell motility in 786-O cells and miR-122 inhibitor hampered cell motility of SN12-PM6 cells. (G) FOXO3 and epithelial-mesenchymal transition-associated proteins levels were measured by western blot analysis following transfection with miR-122 mimics or NC and miR-122 inhibitors or NC. Data are presented as the mean \pm standard deviation $\left(" \mathrm{P}<0.05\right.$ and $\left.{ }^{* * *} \mathrm{P}<0.001\right)$. miR, microRNA; NC, negative control; FOXO3, Forkhead Box O3. 
A

FOX03 3' UTR position (4314-4321) WT 5' AUGAGGCCUCUUGCCACACUCCAGAA $3^{\prime}$
miR-122:
FOX033' UTR position (4314-4321) MUT 5' AUGAGGCCUCUUGCCGCACACGAGAA

C

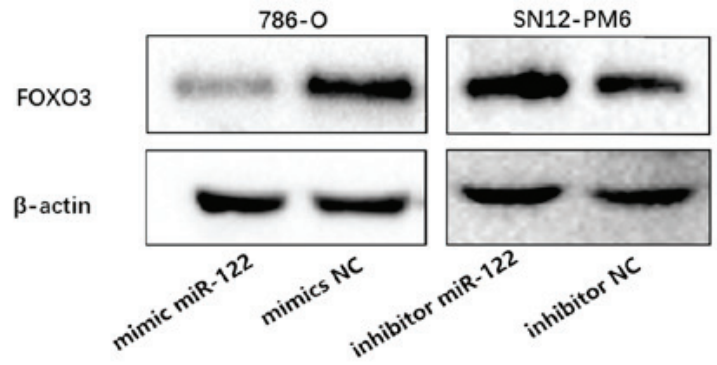

D
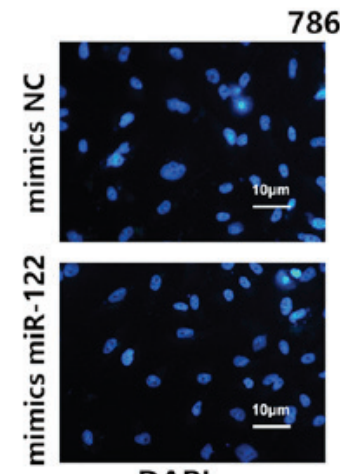

DAPI
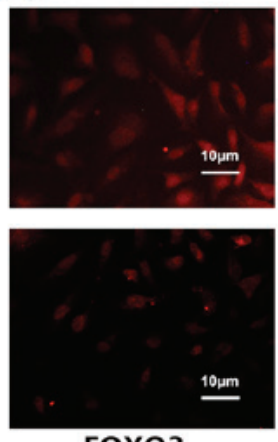

B
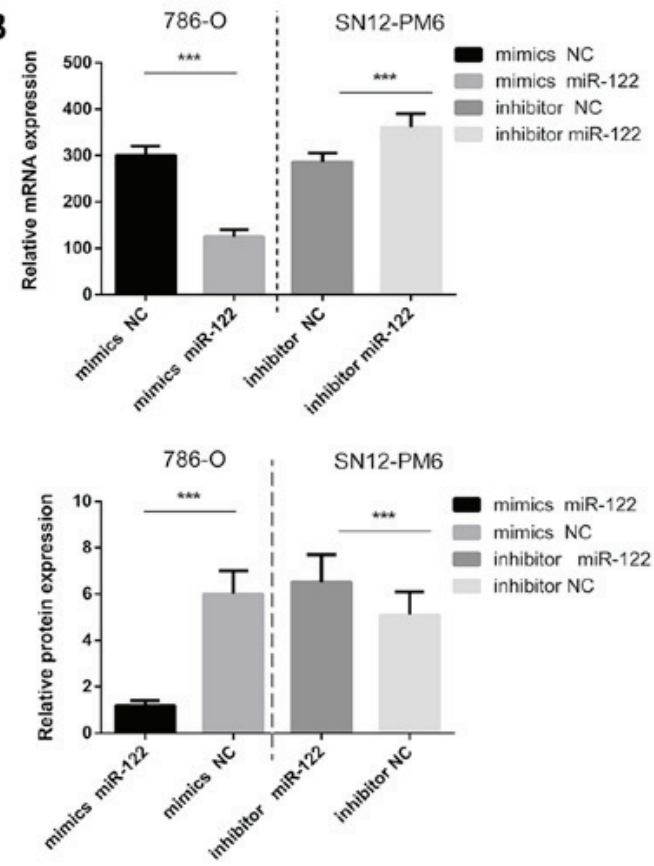

SN12-PM6
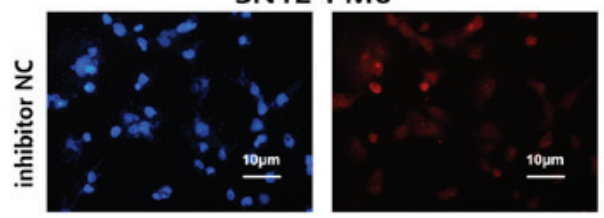

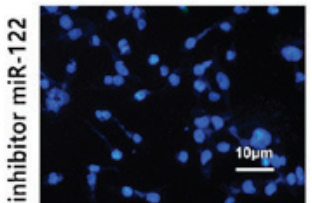

DAPI

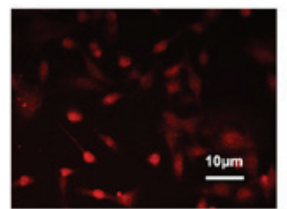

FOXO3

E

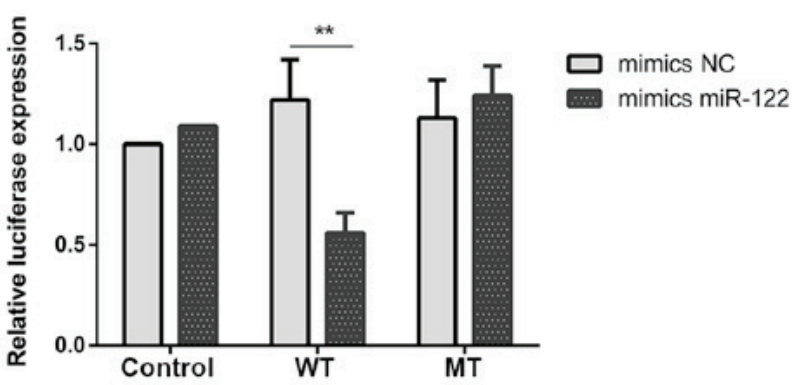

Figure 4. FOXO3 is a direct target of miR-122. (A) Schematic representation of the FOXO3 3'-UTR with WT or MUT putative miR-122 targeting sites, the red letters represent the mutant sites and the bold letters represent the binding sites. (B) Alteration of FOXO3 mRNA levels in 786-O and SN12-PM6 cells following different interference. (C) Changes in FOXO3 protein levels in 786-O and SN12-PM6 cells following transfection of the miR-122 mimics or inhibitor. (D) Representative immunofluorescence staining images of FOXO3 in 786-O and SN12-PM6 cells following transfection with miR-122 mimics or inhibitor. (E) Decreased luciferase reporter activity in 293T cells overexpressing miR-122 following transfection with WT FOXO3 3'-UTR reporter vector. Data are presented as the mean \pm standard deviation $\left({ }^{* *} \mathrm{P}<0.01\right.$ and $\left.{ }^{* * *} \mathrm{P}<0.001\right)$. miR, microRNA; NC, negative control; FOXO3, Forkhead Box O3; UTR, untranslated region; WT, wild-type; MT, mutated.

786-O cells stably transfected with lentiviral miR-122 particles or empty vector were injected subcutaneously into mice. All mice were sacrificed and dissected for tumor collection 8 weeks after injection. The results revealed that miR-122 overexpression in 786-O cells significantly promoted tumor growth and significantly boosted tumor size, compared with the controls $(\mathrm{P}<0.001$; Fig. 6A-C). Because EMT is a crucial mechanism, through which tumors acquire malignancy, the alteration of a number of EMT-association markers upon the overexpression of miR-122, including E-cadherin, N-cadherin and $\alpha$-SMA, were further examined. miR-122 significantly enhanced the expression of $\mathrm{N}$-cadherin and $\alpha$-SMA $(\mathrm{P}<0.001)$ and significantly decreased the expression of E-cadherin $(\mathrm{P}<0.001)$, compared with the EV cells (Fig. 6D). Collectively, the results in vivo indicate that miR-122 promotes EMT in ccRCC cells. 
A

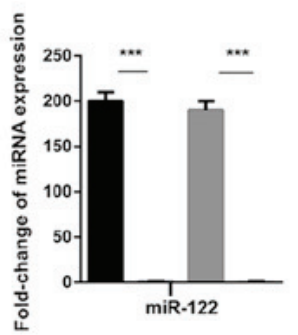

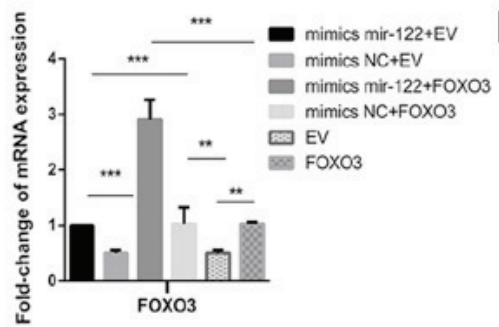

B
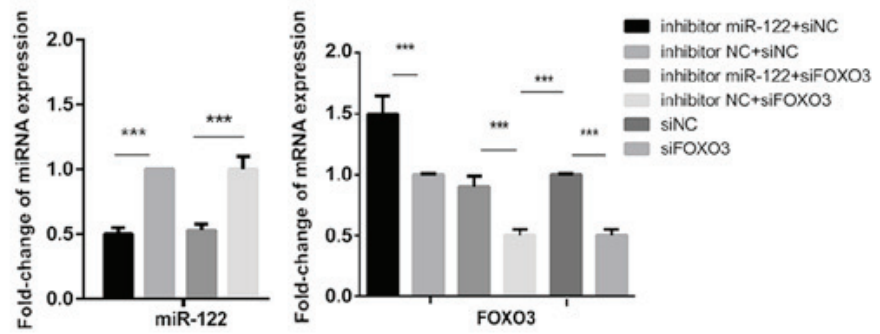

C
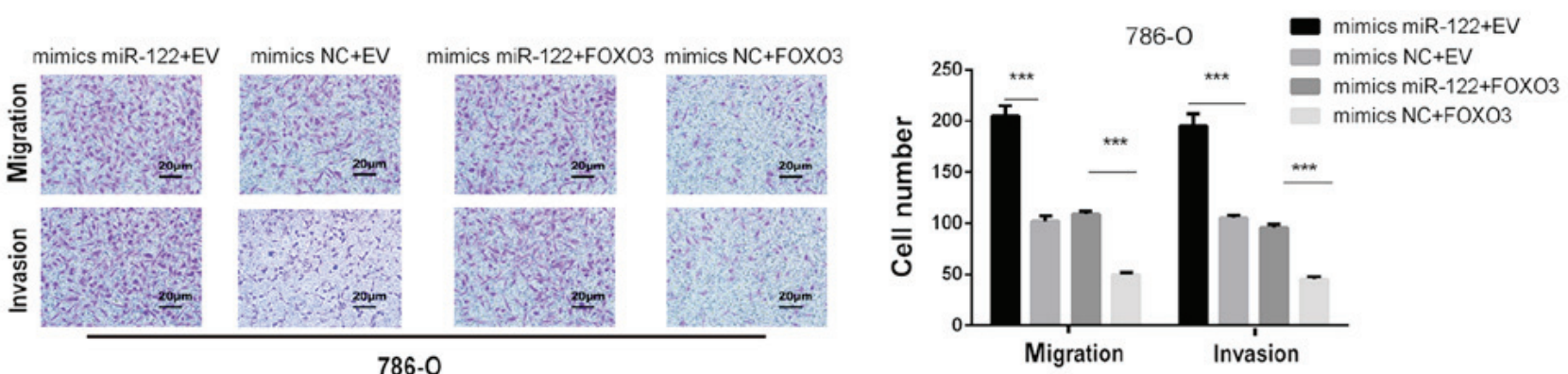

D

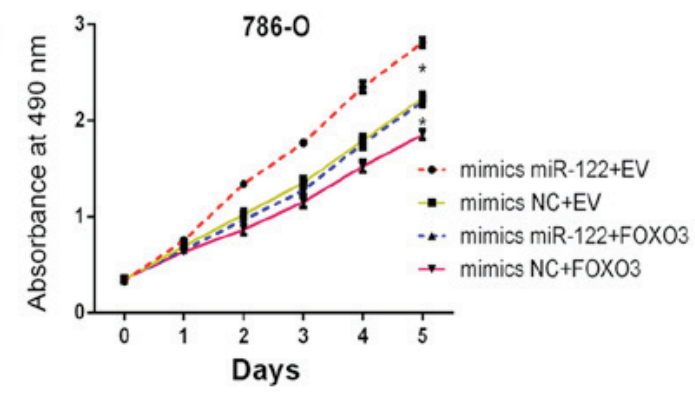

E

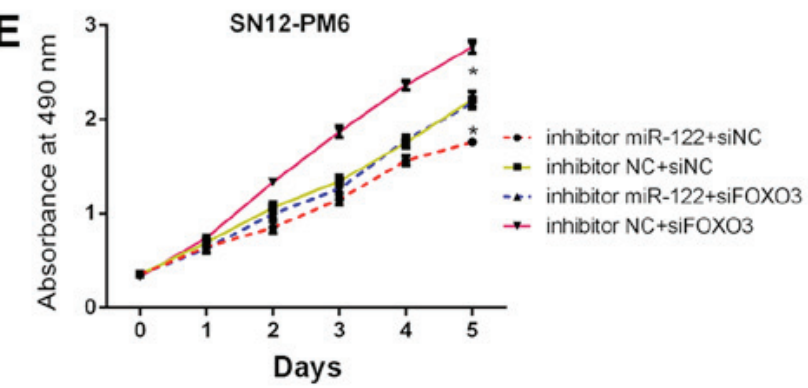

$\mathbf{F}$
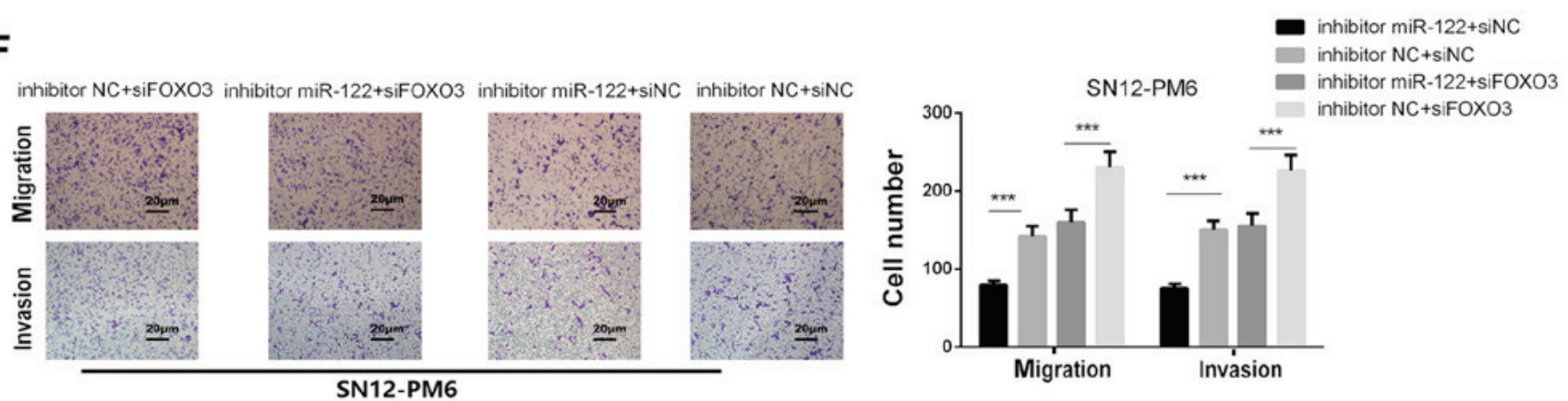

Figure 5. miR-122 promotes tumor proliferation and invasion by downregulating FOXO3. (A) Changes in miR-122 and FOXO3 mRNA levels in 786-O cells following transfection with the miR-122 mimics or NC and the FOXO3 plasmid or EV. (B) Alteration of miR-122 and FOXO3 mRNA level in SN12-PM6 cells following transfection with miR-122 inhibitor or NC and siFOXO3 or siNC. (C) Transwell and Matrigel assays in 786-O cells demonstrated that FOXO3 overexpression hampers the role of miR-122 in promoting migration and invasion in 786-O cells. (D) Overexpression of FOXO3 counteracted miR-122 proliferation promotion in 786-O cells. (E) Inhibition of FOXO3 attenuated the negative effect for proliferation of the miR-122 inhibitor in SN12-PM6 cells. (F) Knockdown of FOXO3 reverses the role of the miR-122 inhibitor on migration and invasion in SN12-PM6 cells. Data are presented as the mean \pm standard deviation $\left({ }^{*} \mathrm{P}<0.05,{ }^{* *} \mathrm{P}<0.01\right.$ and $\left.{ }^{* * *} \mathrm{P}<0.001\right)$. miR, microRNA; NC, negative control; FOXO3, Forkhead Box O3; si, small interfering.

\section{Discussion}

Dysregulation of miRNAs is common in cancer, and miRNAs can serve as a tumor promoter or suppresser $(8,11,19)$. Recent studies revealed that miRNAs may be secreted to circulation, assisting cancer cells in metastasis and colonization $(41,42)$ Reports demonstrated that miR-122 is dysregulated in numerous cancer types, including liver, breast and lung $(15-18,43)$. In hepatocellular carcinoma (HCC), overexpression of miR-122 can induce cell cycle arrest and apoptosis by inhibiting Cyclin $\mathrm{Gl}$ and $\mathrm{Bcl}$-2 like 2 expression (19). Enhanced miR-122 expression can also inhibit HCC cell growth and promote cell cycle arrest by activating the Wnt/B-catenin-TCT signaling pathway (18). Additionally, overexpression of miR-122 was reported to reduce the number of invasion and migration cells in non-small-cell lung cancer (NSCLC) (44). These data support the hypothesis that miR-122 acts as a tumor suppressor in HCC and NSCLC. However, in colorectal cancer (CRC), increased miR-122 levels were associated with a poor prognostic subtype, indicating that miR-122 may act as an oncogene in CRC (16). These data indicated that miR-122 serves an oncogenic or tumor-suppressing role in the progression of cancer. Lian et al (40) demonstrated that miR-122 can promote the proliferation and invasion of 

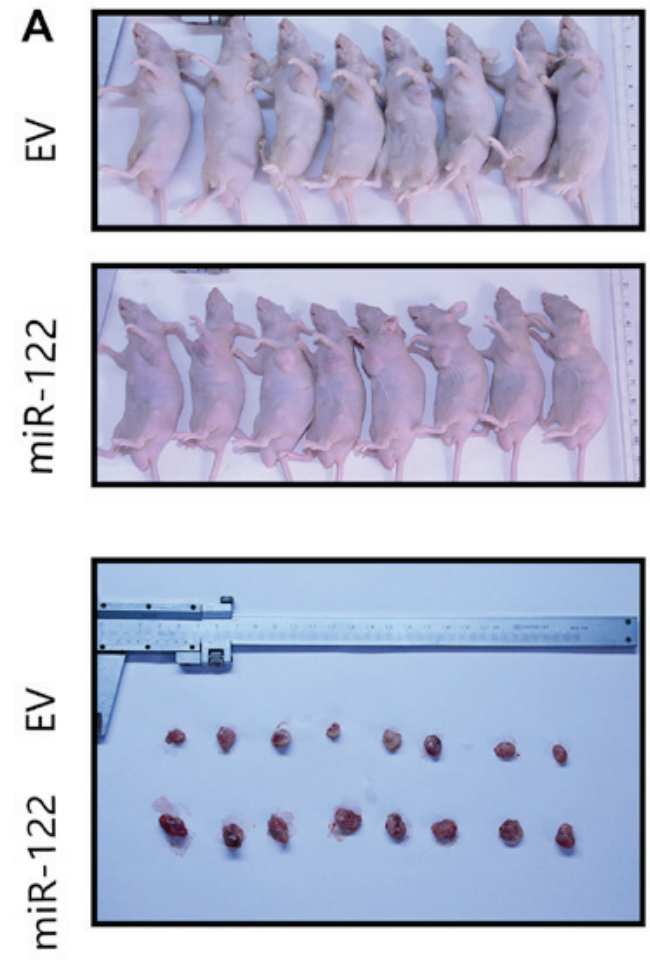

miR-122 Empty vector

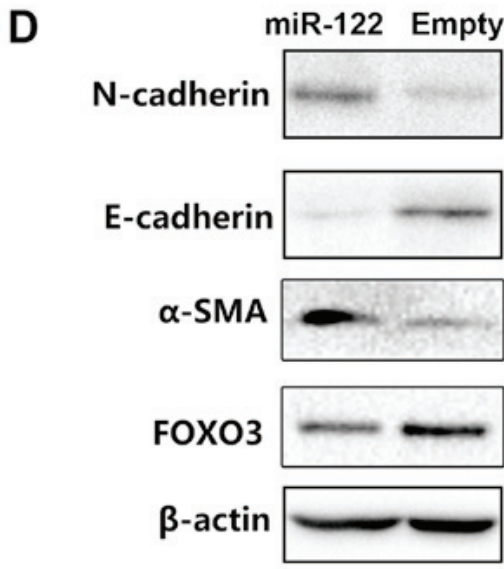

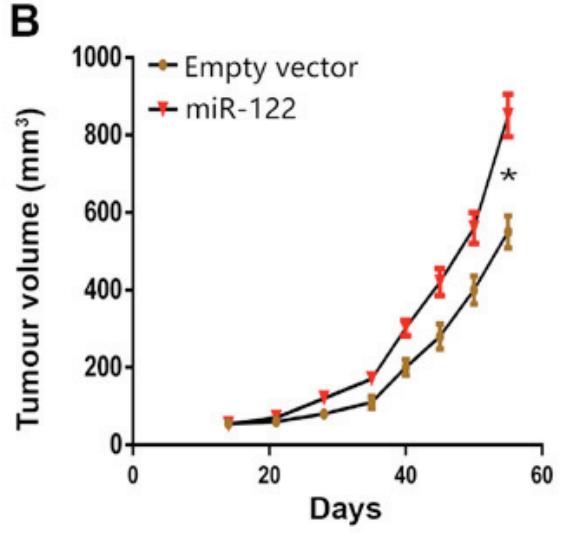

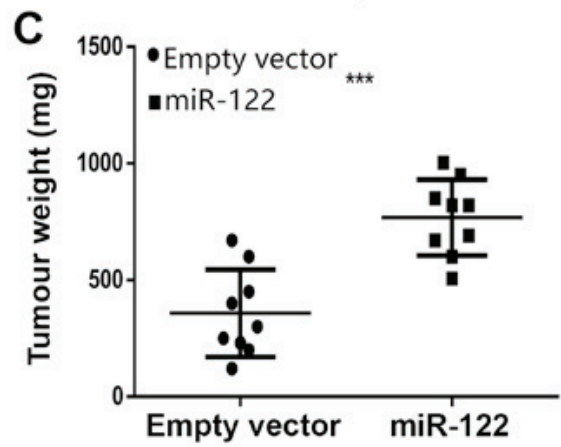

Figure 6. miR-122 promotes tumor growth and cell invasion in vivo. (A) Representative images of nude mice and xenograft tumors derived from subcutaneous injection of 786-O cells injection with plv-miR-122 plasmid or EV. (B) Tumor volumes and (C) weights comparison between miR-122 and EV groups. (D) Western blot analysis demonstrated different protein levels of epithelial-mesenchymal transition-associated markers (E-cadherin, N-cadherin and $\alpha$-SMA) between the groups. Data are presented as the mean \pm standard deviation $\left({ }^{*} \mathrm{P}<0.05\right.$ and $\left.{ }^{* * *} \mathrm{P}<0.001\right)$. miR, microRNA; FOXO3, Forkhead Box O3; $\alpha-\mathrm{SMA}$, $\alpha$-smooth muscle actin.

renal cancer cell lines, but there was not further verification in clinical samples and in vivo experiments. Fan et al (39) demonstrated that miR-122 can promote metastasis of ccRCC by directly targeting Dicer, but they have not explained the screening process of miR-122. In the present study, it was demonstrated that miR-122 is overexpressed in ccRCC by the integrated analysis of four miRNA expression profiles, and, to the best of our knowledge, it was indicated for the first time that FOXO3 is a direct target of miR-122 in ccRCC, which further clarified the mechanism of miR-122 to promote renal cell proliferation and invasion.

The present study used integrated analysis strategy and TCGA-KIRC validation to demonstrate that miR-122 is notably upregulated in ccRCC. Further prognostic analysis of the present ccRCC cohort indicated that high levels of
miR-122 were associated with poor metastasis-free survival time, demonstrating that miR-122 may serve an oncogenic role in ccRCC. Subsequently, in vitro and in vivo experiments were conducted to confirm this hypothesis.

786-O cells that were induced by overexpression of miR-122 demonstrated aggressive growth; but the SN12-PM6 cells had poor growth following miR-122 downregulation. The gene target of miR-122 was predicted to investigate the mechanism underlying miR-122 function in ccRCC. The data recognized FOXO3 as a direct target of miR-122. The present analysis demonstrated a significant inverse correlation between miR-122 and FOXO3 mRNA expression levels in ccRCC $\left(r^{2}=0.05118, P<0.0001\right)$. Reduced miR-122 level demonstrated a positive correlation with increased FOXO3 mRNA level and vice versa. The present study established a notable association 
between miR-122 and FOXO3. Knockdown of miR-122 in SN12-PM6 cells suppressed cell growth and attenuated cell migration and invasion. The dual-luciferase reporter assay indicated that miR-122 could bind to the WT sequence, rather than the MUT sequence, of the target gene. Upregulation of miR-122 in 786-O cells downregulated FOXO3 levels by directly interacting with the 3'-UTR of FOXO3. Therefore, it was concluded that miR-122 regulated $\mathrm{FOXO} 3$ expression by directly binding its 3 '-UTR.

FOXO3 is a member of the FOXO family, which notably regulates the proliferation of cells by modulating its downstream genes, including cyclin-dependent kinases (26). FOXO3 is a critical gene to human longevity, and it participates in numerous human physiology processes, including glucose homeostasis, apoptosis, immunity, stem cell homeostasis, autophagy and tumor suppression $(45,46)$. FOXO3 can suppress tumor growth by steering the induction of p53-dependent apoptosis, increasing Bim expression or downregulating $M y c$, a stimulator of tumor cell proliferation and survival (47).

The present data reveal that miR-122 serves a vital role in tumor progression of ccRCC by negatively regulating its target FOXO3; thus, miR-122 may be considered as a potential therapeutic target for ccRCC.

\section{Acknowledgements}

Not applicable.

\section{Funding}

This work was financially supported by the National Natural Science Foundation of China (grant no. 81402109) and National Natural Science Foundation of China (grant no. 81702494).

\section{Availability of data and materials}

The datasets generated and analyzed during the current study are available from the corresponding author on reasonable request.

\section{Authors' contributions}

$\mathrm{XZ}$ and DN designed the studies. WN primarily performed the experiments, wrote the manuscript and prepared the figures. $\mathrm{XM}, \mathrm{YZ}, \mathrm{YG}$ and CP partially performed the experiments. All authors have read and approved the final version of this manuscript.

\section{Ethics approval and consent to participate}

This study was approved by the Ethics Committee of Chinese People's Liberation Army General Hospital (Beijing, China). Each enrolled patient signed written informed consent prior to sample collection. Animal experiments were approved by the Experimental Animal Ethical Committee of Chinese PLA General Hospital and were conducted in accordance with the Guide for the Care and Use of Laboratory Animals.

\section{Patient consent for publication}

Patients included in the present study consented for publication.

\section{Competing interests}

The authors declare that they have no competing interests.

\section{References}

1. Siegel RL, Miller KD and Jemal A: Cancer Statistics, 2017. CA Cancer J Clin 67: 7-30, 2017.

2. Capitanio U and Montorsi F: Renal cancer. Lancet 387: 894-906, 2016.

3. Escudier B, Motzer RJ, Sharma P, Wagstaff J, Plimack ER, Hammers HJ,Donskov F, Gurney H,Sosman JA,ZalewskiPG, et al: Treatment beyond progression in patients with advanced renal cell carcinoma treated with nivolumab in CheckMate 025. Eur Urol 72: 368-376, 2017.

4. Wells JC, Stukalin I, Norton C, Srinivas S, Lee JL, Donskov F, Bjarnason GA, Yamamoto H, Beuselinck B, Rini BI, et al: Third-line targeted therapy in metastatic renal cell carcinoma: Results from the International Metastatic Renal Cell Carcinoma Database Consortium. Eur Urol 71: 204-209, 2017.

5. Hu F, Xu P, Sun B and Xiao Z: Differences in the MicroRNA profiles of subcutaneous adipose-derived stem cells and omental adipose-derived stem cells. Gene 625: 55-63, 2017.

6. Liang L, Lan F, Yin X, Ge S, Yu J and Yan M: Metal-enhanced fluorescence/visual bimodal platform for multiplexed ultrasensitive detection of microRNA with reusable paper analytical devices. Biosens Bioelectron 95: 181-188, 2017.

7. Tao Y, Yin D, Jin M, Fang J, Dai T, Li Y, Li Y, Pu Q and Xie G: Double-loop hairpin probe and doxorubicin-loaded gold nanoparticles for the ultrasensitive electrochemical sensing of microRNA. Biosens Bioelectron 96: 99-105, 2017.

8. Gattolliat CH, Couvé S, Meurice G, Oréar C, Droin N, Chiquet M, Ferlicot S, Verkarre V, Vasiliu V, Molinié V, et al: Integrative analysis of dysregulated microRNAs and mRNAs in multiple recurrent synchronized renal tumors from patients with von Hippel-Lindau disease. Int J Oncol 53: 1455-1468, 2018.

9. Yi Z, Fu Y, Zhao S, Zhang X and Ma C: Differential expression of miRNA patterns in renal cell carcinoma and nontumorous tissues. J Cancer Res Clin Oncol 136: 855-862, 2010.

10. Lawrie CH, Larrea E, Larrinaga G, Goicoechea I, Arestin M, Fernandez-Mercado M, Hes O, Cáceres F, Manterola L and López JI: Targeted next-generation sequencing and non-coding RNA expression analysis of clear cell papillary renal cell carcinoma suggests distinct pathological mechanisms from other renal tumour subtypes. J Pathol 232: 32-42, 2014.

11. Falzone L Candido S, Salemi R, Basile MS, Scalisi A, McCubrey JA, Torino F, Signorelli SS, Montella M and Libra M: Computational identification of microRNAs associated to both epithelial to mesenchymal transition and NGAL/MMP-9 pathways in bladder cancer. Oncotarget. 7: 72758-72766, 2016.

12. Hafsi S, Candido S, Maestro R, Falzone L, Soua Z, Bonavida B, Spandidos DA and Libra M: Correlation between the overexpression of Yin Yang 1 and the expression levels of miRNAs in Burkitt's lymphoma: A computational study. Oncol Lett. 11: 1021-1025, 2016.

13. Ambade A, Satishchandran A and Szabo G: Alcoholic hepatitis accelerates early hepatobiliary cancer by increasing stemness and miR-122-mediated HIF-1 $\alpha$ activation. Sci Rep 6: 21340, 2016.

14. Elhanati S, Ben-Hamo R, Kanfi Y, Varvak A, Glazz R, Lerrer B, Efroni S and Cohen HY: Reciprocal regulation between SIRT6 and miR-122 controls liver metabolism and predicts hepatocarcinoma prognosis. Cell Reports 14: 234-242, 2016.

15. Hopcraft SE, Azarm KD, Israelow B, Lévêque N, Schwarz MC, Hsu TH, Chambers MT, Sourisseau M, Semler BL and Evans MJ: Viral determinants of miR-122-independent hepatitis $\mathrm{C}$ virus replication. mSphere 1: 1, 2015.

16. Maierthaler M, Benner A, Hoffmeister M, Surowy H, Jansen L, Knebel P, Chang-Claude J, Brenner $\mathrm{H}$ and Burwinkel B: Plasma miR-122 and miR-200 family are prognostic markers in colorectal cancer. Int J Cancer 140: 176-187, 2017.

17. Pan C, Wang X, Shi K, Zheng Y, Li J, Chen Y, Jin L and Pan Z: miR-122 reverses the doxorubicin-resistance in hepatocellular carcinoma cells through regulating the tumor metabolism. PLoS One 11: e0152090, 2016.

18. Ahsani Z, Mohammadi-Yeganeh S, Kia V, Karimkhanloo H, Zarghami N and Paryan M: WNT1 gene from WNT signaling pathway is a direct target of miR-122 in hepatocellular carcinoma. Appl Biochem Biotechnol 181: 884-897, 2017. 
19. von Felden J, Heim D, Schulze K, Krech T, Ewald F, Nashan B, Lohse AW and Wege H: High expression of micro RNA-135A in hepatocellular carcinoma is associated with recurrence within 12 months after resection. BMC Cancer 17: 60, 2017.

20. Fong MY, Zhou W, Liu L, Alontaga AY, Chandra M, Ashby J, Chow A, O'Connor ST, LiS, Chin AR, et al: Breast-cancer-secreted miR-122 reprograms glucose metabolism in premetastatic niche to promote metastasis. Nat Cell Biol 17: 183-194, 2015.

21. Lee CG, Kim JG, Kim HJ, Kwon HK, Cho IJ, Choi DW, Lee WH, Kim WD, Hwang SJ, Choi S, et al: Discovery of an integrative network of microRNAs and transcriptomics changes for acute kidney injury. Kidney Int 86: 943-953, 2014.

22. Du WW, Yang W, Chen Y, Wu ZK, Foster FS, Yang Z, Li X and Yang BB: Foxo3 circular RNA promotes cardiac senescence by modulating multiple factors associated with stress and senescence responses. Eur Heart J 38: 1402-1412, 2017.

23. Hagenbuchner J, Lungkofler L, Kiechl-Kohlendorfer U, Viola G, Ferlin MG, Ausserlechner MJ and Obexer P: The tubulin inhibitor MG-2477 induces autophagy-regulated cell death, ROS accumulation and activation of FOXO3 in neuroblastoma. Oncotarget 8: 32009-32026, 2017.

24. Kumazoe M, Takai M, Bae J, Hiroi S, Huang Y, Takamatsu K, Won Y, Yamashita M, Hidaka S, Yamashita S, et al: FOXO3 is essential for CD44 expression in pancreatic cancer cells. Oncogene 36: 2643-2654, 2017.

25. Kumazoe M, Takai M, Hiroi S, Takeuchi C, Kadomatsu M, Nojiri T, Onda H, Bae J, Huang Y, Takamatsu K, et al: The FOXO3/PGC-1 $\beta$ signaling axis is essential for cancer stem cell properties of pancreatic ductal adenocarcinoma. J Biol Chem 292: 10813-10823, 2017.

26. Coomans de Brachène $\mathrm{A}$ and Demoulin JB: FOXO transcription factors in cancer development and therapy. Cell Mol Life Sci 73: 1159-1172, 2016.

27. Liang R and Ghaffari S: Mitochondria and FOXO3 in stem cell homeostasis, a window into hematopoietic stem cell fate determination. J Bioenerg Biomembr 49: 343-346, 2017.

28. Natarajan SK, Stringham BA, Mohr AM, Wehrkamp CJ, Lu S, Phillippi MA, Harrison-Findik D and Mott JL: FoxO3 increases miR-34a to cause palmitate-induced cholangiocyte lipoapoptosis J Lipid Res 58: 866-875, 2017.

29. Peng XL, So KK, He L, Zhao Y, Zhou J, Li Y, Yao M, Xu B Zhang S, Yao H, et al: MyoD- and FoxO3-mediated hotspot interaction orchestrates super-enhancer activity during myogenic differentiation. Nucleic Acids Res 45: 8785-8805, 2017.

30. Salcher S,Hermann M,Kiechl-Kohlendorfer U,Ausserlechner MJ and Obexer P: C10ORF10/DEPP-mediated ROS accumulation is a critical modulator of FOXO3-induced autophagy. Mol Cancer 16: 95, 2017.

31. Song D, Ma J, Chen L, Guo C, Zhang Y, Chen T, Zhang S, Zhu Z, Tian L and Niu P: FOXO3 promoted mitophagy via nuclear retention induced by manganese chloride in SH-SY5Y cells. Metallomics. 9 1251-1259, 2017.

32. Lee J and Park SH: Tumor-suppressive activity of 1,25-dihydroxyvitamin D3 against kidney cancer cells via up-regulation of FOXO3. Biosci Biotechnol Biochem 80: 1947-1953, 2016.

33. Ni D, Ma X, Li HZ, , Gao Y, Li XT, Zhang Y, Ai Q, Zhang P, Song EL, Huang QB, et al: Downregulation of FOXO3a promotes tumor metastasis and is associated with metastasis-free survival of patients with clear cell renal cell carcinoma. Clin Cancer Res 20: 1779-1790, 2014.
34. Bloomsmith MA, Perlman JE, Hutchinson E and Sharpless M: Behavioral management programs to promote laboratory animal welfare. In: Management of Animal Care and Use Programs in Research, Education, and Testing. Weichbrod RH, Thompson GAH and Norton JN (eds). CRC Press/Taylor \& Francis, Boca Raton, FL, pp63-82, 2018.

35. Lee C, You D, Park J, Jeong IG, Song C, Hong JH, Ahn H and Kim CS: Validation of the 2009 TNM classification for renal cell carcinoma: Comparison with the 2002 TNM classification by concordance index. Korean J Urol 52: 524-530, 2011.

36. Ficarra V, Novara G and Martignoni G: The use of simplified versions of the Fuhrman nuclear grading system in clinical practice requires the agreement of a multidisciplinary panel of experts. Eur Urol 56: 782-784, discussion 784-785, 2009.

37. Zhou Y, Liu Y, Yan H, Li Y, Zhang H, Xu J, Puthiyakunnon S and Chen X: miR-281, an abundant midgut-specific miRNA of the vector mosquito Aedes albopictus enhances dengue virus replication. Parasit Vectors 7: 488, 2014.

38. Wolter JM, Kotagama K, Pierre-Bez AC, Firago M and Mangone M: 3'LIFE: A functional assay to detect miRNA targets in high-throughput. Nucleic Acids Res. 42: e132, 2014.

39. Fan Y, Ma X, Li H, Gao Y, Huang Q, Zhang Y, Bao X, Du Q, Luo G, Liu K, et al: miR-122 promotes metastasis of clear-cell renal cell carcinoma by downregulating Dicer. Int J Cancer 142: 547-560, 2018.

40. Lian JH, Wang WH, Wang JQ, Zhang YH and Li Y: MicroRNA-122 promotes proliferation, invasion and migration of renal cell carcinoma cells through the PI3K/Akt signaling pathway. Asian Pac J Cancer Prev 14: 5017-5021, 2013.

41. Junker K, Heinzelmann J, Beckham C, Ochiya T and Jenster G: Extracellular vesicles and their role in urologic malignancies. Eur Urol 70: 323-331, 2016

42. Qu L, Ding J, Chen C, Wu ZJ, Liu B, Gao Y, Chen W, Liu F, Sun W, Li XF, et al: Exosome-transmitted lncARSR promotes sunitinib resistance in renal cancer by acting as a competing endogenous RNA. Cancer Cell 29: 653-668, 2016.

43. Akuta N, Kawamura Y, Suzuki F, Saitoh S, Arase Y, Kunimoto H, Sorin Y, Fujiyama S, Sezaki H, Hosaka T, et al: Impact of circulating miR-122 for histological features and hepatocellular carcinoma of nonalcoholic fatty liver disease in Japan. Hepatol Int 10: 647-656, 2016.

44. Qin H, Sha J, Jiang C, Gao X, Qu L, Yan H, Xu T, Jiang Q and Gao H: miR-122 inhibits metastasis and epithelial-mesenchymal transition of non-small-cell lung cancer cells. Onco Targets Ther 8: 3175-3184, 2015.

45. Martins R, Lithgow GJ and Link W: Long live FOXO: Unraveling the role of FOXO proteins in aging and longevity. Aging Cell 15: 196-207, 2016

46. Lee $\mathrm{S}$ and Dong HH: FoxO integration of insulin signaling with glucose and lipid metabolism. J Endocrinol 233: R67-R79, 2017.

47. Morris BJ, Willcox DC, Donlon TA and Willcox BJ: FOXO3: A major gene for human longevity - A mini-review. Gerontology 61: 515-525, 2015.

This work is licensed under a Creative Commons Attribution-NonCommercial-NoDerivatives 4.0 International (CC BY-NC-ND 4.0) License. 